\title{
RELIGIOGRAFIA DA COMPARTIMENTAÇÃO DA CONTRIBUIÇÃO FEMININA NAS CIÊNCIAS DA RELIGIÃO NO BRASIL
}

\author{
Maurílio Ribeiro da Silva*
}

\section{RESUMO}

Este não é um artigo feminista. Nenhum homem escreveria com tal propriedade. Trata-se de um exercício religiográfico caracterizado pela tentativa de isenção e neutralidade, tanto quanto isso é possível. O tom de mea culpa vem da análise religiográfica da contribuição feminina nos estudos da religião no Brasil, especificamente na participação da mais importante obra da área, o Compêndio de Ciência da Religião. Para atingir o objetivo, apresentamos questões de ordem epistemológica que buscam a fundamentação e caracterização das Ciências da Religião. Em seguida, apresentamos a definição da Religiografia e sua aplicabilidade como método auxiliar nas pesquisas quantitativas dos estudos da religião. A partir dessa base, propomos um exercício religiográfico, onde demonstramos estatisticamente a compartimentação da atuação das pesquisadoras brasileiras.

Palavras-chave: Religiografia; epistemologia; compartimentação; pesquisas feministas.

\section{RELIGIOGRAPHY OF THE COMPARTMENTALIZATION OF THE FEMININE CONTRIBUITION IN THE SCIENCES OF RELIGION IN BRAZIL}

\section{ABSTRACT}

This is not a feminist article. No man would write with such property. It is a religiographic exercise characterized by an attempt at impartiality and neutrality, as far as it is possible. The tone of mea culpa comes from the religiographic analysis of the female contribution to the studies of religion in Brazil, specifically the participation in the most important work in the area, the Compendium of Science of Re-

* Doutorando e Mestre em Ciências da Religião pelo Programa de Pós-Graduação em Ciências da Religião da Pontifícia Universidade Católica de Minas Gerais (PUC-MG). Graduado em Teologia pelo Instituto Metodista Izabela Hendrix. 
ligion. In order to achieve the objective, we present epistemological questions on the foundation and characterization of the Sciences of Religion. Then, we present the definition of Religiography and its applicability as an auxiliary method to quantitative researches on the studies of religion. From this basis we propose a religiographic exercise, where we demonstrate statistically the compartmentalization of the performance of Brazilian female researchers.

Keywords: Religiography; epistemology; compartmentation; feminist research.

\section{RELIGIOGRAFÍA DE LA COMPARTIMENTACÍON DE LA CONTRIBUCIÓN FEMENINA EM LAS CIENCIAS DE LA RELIGIÓN EM EL BRASIL}

\section{RESUMEN}

Este no es un artículo feminista. Ningún hombre escribiría con tal propiedad. Es un ejercicio religioso caracterizado por un intento de imparcialidad y neutralidad, en la medida de lo posible. El tono del mea culpa proviene del análisis religiográfico de la contribución femenina a los estudios de religión en Brasil, específicamente la participación en el trabajo más importante del área, el Compendio de Ciencia de la Religión. Para lograr el objetivo, presentamos preguntas epistemológicas que buscan el fundamento y la caracterización de las Ciencias de la Religión. A continuación presentamos la definición de Religiografía y su aplicabilidad como método auxiliar en la investigación cuantitativa de los estudios de la religión. A partir de esta base proponemos un ejercicio religioso, donde demostramos estadísticamente la compartimentación de la actuación de los investigadores brasileños.

Palabras clave: eligiografía; epistemología; compartimentación; investigación feminista.

\section{INTRODUÇÃO}

O holandês Pierre Daniel Chantepie de la Saussaye, considerado um dos fundadores da Ciência da Religião, indicava em 1891, em seu Manual of the Sciense of Religion (Manual de Ciência da Religião), que a disciplina nasceu sob o espectro de determinados problemas epistemológicos. Para Saussaye (1891), apesar do reconhecimento e da institucionalização acadêmico/institucional, a disciplina dava seus primeiros passos no 
campo dos estudos científicos da religião. Essa característica neófita da disciplina evidenciava o caráter inacabado de determinadas questões teóricas e metodológicas que precisavam evoluir até que a Ciência da Religião alcançasse a totalidade de sua evolução e o reconhecimento de seu lugar entre as ciências humanas.

Essa questão de ordem epistemológica e institucional apresentada por Saussaye foi relativamente vencida na Europa, porém, ainda reflete a realidade das Ciências da Religião no contexto acadêmico/institucional brasileiro. Instituída no final da década de 1970, a Ciência da Religião conta com pouco mais de 40 anos de atividade acadêmica, o que a torna uma ciência "ainda instável se considerada em nível mundial" (Luiz Henrique DREHER, 2008, p. 168) e, por causa disso, é vista com certa indiferença nas esferas científico/institucionais. Também nesse sentido, Antônio Gouveia de Mendonça, em palestra dada aos/às pósgraduandos/as em Ciências da Religião, afirmou que a disciplina "por ora não oferece nenhuma definição de si mesma” (2004, p. 18). Marcelo Camurça (2008), por sua vez, considera que as Ciências da Religião ainda são uma ciência em construção.

Além do fato de ser uma ciência nova no Brasil, as Ciências da Religião nasceram a partir da proximidade e da tutela político/institucional da teologia. Os primeiros programas de pós-graduação surgiram sob a ação de Instituições de Ensino Superior (IES) confessionais católicas e protestantes. De acordo com Mendonça (Ângela MARQUES; Marcelo ROCHA, 2007), as institucionalizações foram precedidas por grupos de estudo fundados pelas igrejas históricas que buscavam a compreensão do fenômeno religioso. Some-se a isso a ação de teólogos da libertação, que encontraram nas Ciências da Religião um local apropriado para a pesquisa científica da religião, abrigados das intervenções de natureza eclesiástica (Amauri FERREIRA; Flávio SENRA, 2012). José J. Queiroz, um dos fundadores dos programas de pós-graduação em Ciências da Religião no Brasil, considera que essa proximidade com a teologia, além de existir, era tratada de forma natural, sendo percebida na metodologia de análise da sociedade e da religião diferenciação reside apenas nas questões de enfoque da pesquisa (Ângela MARQUES; Marcelo ROCHA, 2007). 
Em virtude dessas questões, e também pelo fato de a disciplina ter sido desenvolvida no Brasil "sem uma crítica prévia ou qualquer análise de seus pressupostos" (Mendonça, citado por Ângela MARQUES; Marcelo ROCHA, 2007, p. 208), é que esforços foram envidados nos anos seguintes com o propósito de consolidar epistemologicamente as Ciências da Religião no contexto científico/institucional brasileiro. Chamamos a atenção para quatro pontos: 1) a participação feminina no processo de instituição das Ciências da Religião no Brasil, como por exemplo, a atuação das pesquisadoras Beatriz Muniz de Souza e Maria Isaura Pereira de Queiroz; 2) a escassez de registros históricos dessa participação feminina no período de institucionalização da disciplina; 3) a participação feminina no debate epistemológico, teórico e metodológico da área, cujo ápice foi a publicação do Compêndio de Ciência da Religião no ano de 2013, organizado por iniciativa dos professores da PUC SP, João Décio Passos e Frank Usarski; 4) a compartimentação do espaço acadêmico/profissional concedido às pesquisadoras da religião, cuja contribuição ficou restrita às ciências auxiliares dos estudos da religião.

Antes de adentrar as questões religiográficas dos estudos femininos da religião, é necessário pontuar algumas questões epistemológicas e apresentar uma conceituação do termo religiografia, ressaltando a sua utilização como método de análise qualitativa e quantitativa das pesquisas no campo das Ciências da Religião.

\section{QUESTÕES EPISTEMOLÓGICAS DAS CIÊNCIAS DA RELIGIÃO}

Pode-se considerar que "Toda ciência possui um estatuto de conhecimento que a considera como uma área do saber" (Amauri FERREIRA; Flávio SENRA, 2013, p. 5). Esse estatuto é uma demarcação, uma fronteira estabelecida que aponta o alcance e os limites de uma ciência, ainda que a interdisciplinaridade, que é a interação e o diálogo de uma ciência com outras seja necessária.

As questões epistemológicas e os estudos metateóricos são contingenciais, já que nenhuma ciência subsiste em função dos debates normativos de sua constituição. As grandes contribuições científicas de Nicolau Copérnico, Isaac Newton, Charles Darwin e Albert Einstein para a humanidade não vieram dos debates epistemológicos ou meto- 
dológicos da Astronomia, da Matemática, da Biologia ou da Física. O trabalho de pesquisa desses cientistas se caracterizou pela utilização de fundamentos e pressupostos científicos, de métodos de pesquisa, análise e experimentação vigentes em seu tempo. Porém, eles também desenvolveram criativamente novos métodos, metodologias e técnicas, ou seja, novos elementos epistemológicos sem os quais suas pesquisas não alcançariam o êxito obtido. Esses avanços epistemológicos, considerados a partir da teoria das revoluções científicas, são "episódios de desenvolvimento em que um paradigma mais antigo é substituído, no todo ou em parte, por um novo paradigma incompatível com o anterior" (Thomas, KUHM, 1996, p. 92, tradução nossa). Essa substituição paradigmática significa também um novo modo de compreensão do mundo (Thomas, KUHN, 1996).

As questões sobre o estatuto epistemológico surgem em virtude da falta de problematização inicial acerca do fundamento de uma área, ou mesmo pelo abandono desses fundamentos diante da evolução, ou, descaracterização de uma ciência. O estabelecimento de regras epistemológicas define possibilidades, pontos de convergências, divergência e interações. A formulação teórico epistemológica busca não só a fundamentação, como também a compreensão dos objetivos, dos objetos, da consolidação e do avanço de uma ciência. Essa formulação se dá por meio de determinadas virtudes epistemológicas (Jeep JENSEN; Eduardo (RUZ, 2013), que são: 1) sensibilidade para com o fato empírico; 2) premissas de fundo plausíveis; 3) coerência com outras coisas que conhecemos; 4) exposição a críticas das mais variadas fontes; 5) incorporação de virtudes como a objetividade, imparcialidade, honestidade intelectual, reflexividade e autocrítica; 6) clarificação dos estudos, métodos e objeto.

Para Luiz Felipe Pondé (2008), a epistemologia aponta para os limites cognitivos do ser humano, e esses limites se estendem também para as áreas de pesquisa. Nesse sentido, estabelecer um estatuto epistemológico visa fornecer critérios de validade, bases seguras, normas de ação e suporte epistêmico, sem as quais o/a pesquisador/a correria

Developmental episodes in which an older paradigm is replaced in whole or in part by an incompatible new one. 
o risco da divagação em suas pesquisas. Esse estatuto deve clarificar questões de métodos e metodologias, definição de objetos e objetivos de pesquisa, além de critérios de avaliação.

Apesar de seu caráter normativo, o estatuto epistemológico responde a questões de ordem política, contextual, institucional e regional. Não se trata de um conhecimento apartado de realidades humanas distintas. No entanto, essas realidades humanas devem responder a condições de “paridade epistêmica e igualdade evidencial” (Alexandre JUNGES, 2013, p. 614). Os envolvidos (pares epistêmicos) na demanda epistemológica devem possuir o domínio do tema e partir da mesma evidência na busca do estabelecimento de um estatuto epistemológico. Em outras palavras, os/as atores/as devem fazer parte da mesma peça. Não é a História, a Sociologia ou a Antropologia que vão definir o estatuto epistemológico das Ciências da Religião. Ainda que colaborem e forneçam métodos e ferramentas importantes de análise, o/a sociólogo/a e o/a antropólogo/a não são pares epistêmicos do/a cientista da religião.

Assim, podemos estender esse entendimento e questionar: seria o estatuto epistemológico alemão, francês ou inglês aplicável à realidade acadêmica e social brasileira? Ainda que se corra o risco do relativismo epistemológico, compreendido aqui como a perspectiva da subordinação do conhecimento ao tempo, lugar, sociedade, cultura e experiência pessoal, consideramos correta a proposta de um "contrato epistemológico" (Luiz Felipe PONDÉ, 2008, p. 28) aliado à questão da paridade epistêmica (Alexandre JUNGES, 2013).

Compreendemos a necessidade de se estabelecer debates sobre as questões epistemológicas a partir da análise do que a própria área de Ciências da Religião produz, e do perfil epistemológico delineado por seus/as pesquisadores/as através dos Programas de Pós-graduação stricto sensu em Ciências da Religião no Brasil. Busca-se, também, apresentar o papel das mulheres pesquisadoras para o estabelecimento do estatuto epistemológico das Ciências da Religião no Brasil.

A fundação das Ciências da Religião no Brasil, conforme declarado por seus pioneiros (Ângela MARQUES; Marcelo ROCHA, 2007), não foi precedida de debates epistemológicos que determinassem a autonomia da área. Nem mesmo autonomia física foi possível, já que as primeiras 
instituições a acolherem a nova ciência eram instituições confessionais católicas e protestantes e, em certos casos, movidas também por interesses eclesiásticos. $O$ fato de iniciar dessa forma justifica mais ainda o acirramento das questões epistemológicas.

Não desconsideramos o fato de que, após 40 anos de história, as Ciências da Religião atingiram certa autonomia acadêmica e científica, se desvencilhando de determinadas facetas do pensamento teológico, filosófico e sociológico. Entretanto, ainda há a necessidade de análise do campo da teoria do conhecimento e do estabelecimento de um perfil epistemológico melhor definido para a área. Consideramos que essa definição deve partir do interior da própria área, de seus pares epistêmicos, ou seja, dos/as docentes envolvidos com as pesquisas e a formação na área de Ciências da Religião.

\section{RELIGIOGRAFIA DAS CIÊNCIAS DA RELIGIÃO}

A fim de elucidar melhor as questões relativas à utilização do termo religiografia, esclarecemos que o termo se explica, justifica e, de certo modo, se funde com as atividades desenvolvidas pelo prof. Dr. Flávio Augusto Senra Ribeiro em suas atividades como Coordenador da área de Ciências da Religião e Teologia junto à Coordenação de Aperfeiçoamento de Pessoal de Nível Superior (CAPES). Quatro de seus artigos são voltados à análise religiográfica da área e dos programas: 1) Programas profissionais. Situação atual e perspectivas na área Ciências da Religião e Teologia no Brasil; 2) O teólogo e o cientista da religião. Religiografia acerca das interfaces entre Ciências da Religião ou Religiografia e Teologia no Brasil; 3) Estudos de Ciências da Religião e Teologia no Brasil: situação atual e perspectivas; 4) O estado atual dos programas de Teologia e Ciência(s) da(s) Religião(ões) no Brasil - 2013-2014: aproximações.

Destacamos três conceituações do vocábulo religiografia desenvolvidas em seus artigos:

Análise do que se produz em Ciência(s) da(s) Religião(ões), seus métodos, interpretações, epistemologias, modos de atuação e perfil de seus estudiosos (Flávio SENRA, 2016, p. 8). 
Trata-se de uma proposição metodológica para reconhecer os estudos que tratam das pesquisas de natureza científica sobre a religião desenvolvidos por religiólogos (cientistas da/as Religião/ões); pesquisas relacionadas ao estado da arte da pesquisa na área; a descrição ou o relato que faz de si mesmo o campo de estudos da(s) religião(ões); a análise do que se produz em Ciência(s) da(s) Religião(ões), seus métodos, interpretações, epistemologias, modos de atuação e perfil de seus estudiosos/as. Enfim, trata-se de investigar de que forma se faz ciência nesta área do conhecimento, com que critérios se escolhem teorias e métodos de pesquisa (Flávio SENRA, 2016, p. 112).

O termo religiografia deve designar o tipo de investigação que se concentra na sistematização e análise da produção realizada por autores/as do campo de estudos da religião, bem como sobre o perfil da produção ou o estado da arte em algum tema no campo dos estudos da religião (Flávio SENRA, 2016, p. 115).

A partir dessas conceituações, desenvolvemos um símile de verbete: trata-se de um olhar atento e analítico do/a pesquisador/a nos aspectos qualitativos, quantitativos e estatísticos das questões que envolvem os desenvolvimentos ou retrocessos da área, o perfil do/a egresso/a, discente e docente, as produções acadêmicas docentes e discentes e suas relações, a epistemologia da área, as metodologias utilizadas nas pesquisas e o perfil teórico das disciplinas e linhas de pesquisa envolvidas nos estudos da religião. A religiografia é uma pesquisa de análise metateórica necessária para as Ciências da Religião, na mesma medida em que exames médicos periódicos são necessários à manutenção do corpo humano. De igual modo, assim como os exames médicos pouco tem a dizer sem a interpretação analítica do/a especialista médico/a, as constatações metateóricas, dados e estatísticas produzidas pouco tem a dizer sem a interpretação analítica do/a pesquisador/a da religião. Trata-se, também, de uma proposição metodológica. Dessa forma, afirmamos não ser justificável o temor de que se trate de um neologismo voltado à substituição da nomenclatura da área, que já ela possui três designações distintas (Ciência da Religião, Ciências da Religião e Ciências das Religiões). Trata-se, exclusivamente, de um método específico de pesquisa já em voga nas produções científicas internacionais. Esse 
método, como ferramenta para a pesquisa, pode ser utilizado na análise teórica e estatística do fenômeno religioso, e nas questões administrativas e pedagógicas de cada programa (subsídios na estruturação de grades curriculares, linhas de pesquisa, grupos de pesquisa, análises de eventos e publicações, etc.).

Este estudo é de natureza descritiva e estatística (Antônio Carlos GIL, 2002), caracterizado como um estudo misto, qualitativo e quantitativo. O estudo objetiva tanto a descrição das características das pesquisas e dos/as pesquisadores/as, como o estabelecimento de relações entre as variáveis, que serão estabelecidas por meio de cruzamentos estatísticos.

De acordo com Antônio Arnot Crespo (1996), a estatística faz parte da matemática aplicada e tem como função a coleta, a organização, a descrição, a análise e a interpretação de dados. As técnicas estatísticas permitem a elaboração de conclusões que transcendem os dados obtidos inicialmente, podendo "estender-se para além da amostra considerada" (Antônio Carlos GIL, 2002, p. 160). Essas conclusões permitem estabelecer um diagnóstico substanciado sobre determinado problema, formular hipóteses, soluções e ações efetivas e apropriadas para esse problema.

\section{RELIGIOGRAFIA DAS PESQUISAS FEMINISTAS DA RELIGIÃO}

A despeito de toda uma história de enfrentamentos e lutas, a questão feminista ganhou projeção mundial e atenção acadêmica a partir dos anos de 1970, inicialmente nos Estados Unidos e no Canadá. Daí em diante, elas incidiram diretamente sobre a compreensão e o modo do fazer científico, ocasionando o aumento substancial de publicações e o desenvolvimento de métodos e abordagens distintas. Uma das áreas influenciadas por essas questões foi a dos estudos da religião, tanto o estudo teológico como o estudo científico. Nesse sentido podemos destacar a contribuição de Anne Pasquier, Elaine Pagels, Émilien Lamirande, Flore Dupriez, Elizabeth A.Clarck, Christine Dowing, Sarah Belanger, Marie-Adrée Roy, Mary Daly, María Lugones, Yuderkis Minoso, Rita Laura Segato, Ochy Curiel, Nancy Auer Falk, Denise Veillette, Rita M. Gross, Danièle Hervieu-Léger, entre outras. No Brasil, podemos citar as pioneiras do período de institucionalização: Beatriz Muniz de Souza e Maria Isaura Pereira de Queiroz, e contemporaneamente, Maria José Rosado, Anete Roese, Sandra Duarte de Souza, dentre outras. 
As teorias feministas, no contexto das Ciências da Religião, compreendem a religião em seu aspecto mediador do mundo e do ser humano a partir da perspectiva, das práticas, da religiosidade e da história feminista (Ana Ester FREIRE, 2015). Uma vez que a religião pode ser considerada um sistema de trocas simbólicas, portanto, envolta num jogo variado de interesses (Sandra Duarte SOUZA, 2004), os estudos feministas da religião encontraram pela frente a predominância do pensamento masculino no contexto judaico-cristão, o que incidiu diretamente sobre as abordagens das pesquisas realizadas e promoveu uma compartimentação da recepção das pesquisas feministas (e também femininas) ${ }^{2}$.

As pesquisas feministas sobre o fenômeno religioso, a despeito das demais ciências pós-modernas, caracterizam-se pelas alterações epistemológicas e metodológicas que influem na percepção da realidade e da necessidade, por vezes, de construções hermenêuticas e metodológicas do conhecimento para firmar essas alterações nas instituições. Para esse intento, é necessário “colocar novas questões, ajustar métodos adequados, formular novas teorias frequentemente surpreendentes, visto ser o campo ainda desconhecido ou mal conhecido por aqueles e aquelas que não o frequentam, manter unidas teoria e práxis" (Èlizabeth LACELLE, 2002, p. 31). Assim exposto, "O feminismo não apenas tem produzido uma crítica contundente ao modo dominante de produção do conhecimento científico, como também propõe um modo alternativo de operação e articulação nesta esfera" (Margareth RAGO, 1998, p.3 ). Compreende-se, dessa forma, que as pesquisas feministas partem tanto de novas epistemologias e novas abordagens do fazer científico, como da manutenção do rigor de determinados pressupostos e métodos.

O tratamento religiográfico dos dados quantitativos através do método estatístico, uma das técnicas do método religiográfico, permite diagnosticar determinados problemas que transcendem os dados obtidos inicialmente, e formular hipóteses, justificativas e ações efetivas na elucidação dos problemas. O método religiográfico não esgota as

\footnotetext{
Aqui propomos uma distinção técnica entre as pesquisas feministas e as pesquisas femininas, tendo em vista que nem todas as pesquisadoras seguem uma agenda feminista no sentido ideológico e de alterações epistemológico/metodológicas nas pesquisas.
} 
possibilidades da pesquisa, nem busca estabelecer conceitos e teorias que se pretendam universais (Gilson CIARALLO, 2009). Os fenômenos humanos e sociais são multiformes e variáveis, não podendo ser totalmente delineados e comportados em números, equações e estatísticas.

A representação qualitativo-estatística do método religiográfico aplicado aos dados oficiais disponibilizados no Sistema Nacional de Pós-Graduação publicados em 2017 pela Coordenação de Aperfeiçoamento de Pessoal de Nível Superior (CAPES) apontou a superioridade quantitativa feminina nos estudos pós-graduados no Brasil.

Tabela 1 - Dados oficiais do Sistema Nacional de Pós-Graduação

\begin{tabular}{c|c|c|c|c|c|c|c}
\hline \multicolumn{1}{c|}{ Sexo } & \multicolumn{2}{|c|}{ Doutorado } & \multicolumn{2}{c|}{ Mestrado } & \multicolumn{2}{c|}{ Mestrado Profissional } & Total Geral \\
\hline & Matriculado & Titulado & Matriculado & Titulado & Matriculado & Titulado & proporção \\
\hline Feminino & 54491 & 10141 & 66439 & 26443 & 13529 & 4376 & 175419 \\
\hline Masculino & 47877 & 8484 & 55175 & 20215 & 14390 & 4095 & 150236 \\
\hline Quantitativo & 102368 & 18625 & 121614 & 46658 & 27919 & 8471 & 325655 \\
\hline \% Feminina & $53,2 \%$ & $54,4 \%$ & $54,6 \%$ & $56,7 \%$ & $48,5 \%$ & $51,7 \%$ & $53,9 \%$ \\
\hline \% Masculina & $46,8 \%$ & $45,6 \%$ & $45,4 \%$ & $43,3 \%$ & $51,5 \%$ & $48,3 \%$ & $46,1 \%$ \\
\hline
\end{tabular}

Fonte: CAPES/MEC e Plataforma Sucupira, 2017.

Os números relativos até o ano de 2015 indicam o total de 175.419 mulheres matriculadas e tituladas nos cursos de mestrado, mestrado profissional e doutorado, correspondendo a 53,9\% do efetivo total, contra 150.236 homens, $46,1 \%$ do efetivo total. O total demonstra que há um excedente feminino de 25.183 mulheres, correspondendo ao percentual geral de $7,8 \%$ a mais de pós-graduandas. A única modalidade que apresentou um efetivo masculino maior foi a de matriculados no mestrado profissional, onde a presença masculina superou em 3,4\% a presença feminina. $O$ número de titulações femininas, em todas as modalidades, mesmo no mestrado profissional, é superior ao das titulações masculinas.

A despeito da superioridade quantitativa feminina nos cursos de pós-graduação stricto sensu, o quadro docente permanente dos programas 
de pós-graduação em Ciências da Religião no Brasil, composto por 124 docentes, é predominantemente masculino, contando com 97 docentes masculinos, $78,2 \%$ do efetivo total, e 27 docentes femininas, correspondendo a $21,8 \%$ do efetivo total, conforme demonstrado na tabela abaixo.

\section{Tabela 2 - Corpo docente permanente dos PPGCR em Ciências da Religião no Brasil}

\begin{tabular}{l|c|c|c|c|c}
\hline \multicolumn{1}{c|}{ IES } & $\begin{array}{c}\text { Total } \\
\text { docente }\end{array}$ & Masculino & Feminino & $\%$ Masculino & \% Feminino \\
\hline PUC SP & 11 & 09 & 02 & 81,8 & 18,2 \\
\hline UMESP & 12 & 09 & 03 & 75,0 & 25,0 \\
\hline UFJF & 17 & 14 & 03 & 82,4 & 17,6 \\
\hline PUC GO & 12 & 08 & 04 & 66,7 & 33,3 \\
\hline UFPB & 11 & 05 & 06 & 45,5 & 54,5 \\
\hline UNICAP & 11 & 09 & 02 & 81,8 & 18,2 \\
\hline PUC & 11 & 10 & 01 & 90,9 & 9,1 \\
MINAS & 12 & 11 & 01 & 91,7 & 8,3 \\
\hline FUV & 09 & 06 & 03 & 66,7 & 33,3 \\
\hline UEPA & 08 & 08 & 00 & 100 & 00 \\
\hline UFS & 10 & 08 & 02 & 80 & 20 \\
\hline PUC CAMP & $\mathbf{1 2 4}$ & $\mathbf{9 7}$ & $\mathbf{2 7}$ & Média & Média \\
\hline Total & $\mathbf{1 0 0 \%}$ & $\mathbf{7 8 , 2} \%$ & $\mathbf{2 1 , 8 \%}$ & $\mathbf{7 8 , 4}$ & $\mathbf{2 1 , 6}$ \\
\hline Proporção & & & &
\end{tabular}

Fonte: dados da CAPES/MEC e Plataforma Sucupira.

Diante das questões epistemológicas expostas no início desse artigo, observa-se que nos últimos anos foram empreendidos esforços, debates e pesquisas metateóricas buscando a reflexão e a discussão de um estatuto epistemológico próprio das Ciências da Religião. Nesse sentido, vale mencionar as obras: Constituintes da Ciência da Religião (2006); a tradução de O que é Ciência da Religião? (2006); As Ciências da Religião no Brasil (2008); O Espectro Disciplinar da Ciência da Religião (2007); dentre outras obras e artigos. Entretanto, o ápice desses esforços 
foi a publicação do Compêndio de Ciência da Religião no ano de 2013. Esse esforço conjunto teve como organizadores os docentes da PUC SP, João Décio Passos e Frank Usarski. Conforme citado pelos autores na Introdução Geral do Compêndio, trata-se de um empreendimento científico coletivo realizado por especialistas em segmentos diversos do conhecimento, e que busca estabelecer critérios de coerência entre os elementos constituintes e o estado atual da Ciência da Religião (João Décio PASSOS; Frank USARSKI, 2013).

São inegáveis as contribuições do Compêndio para a construção do conhecimento sobre as diversas facetas dos estudos da religião. Não há espaço nesse artigo para tratarmos de sua importância e desdobramentos para a área. Buscamos demonstrar religiograficamente nossa hipótese, de que há uma compartimentação do espaço acadêmico/ profissional concedido às pesquisadoras da religião.

$\mathrm{Na}$ tabela 1 demonstramos a supremacia quantitativa feminina de matriculados e titulados na pós-graduação stricto sensu no Brasil³, correspondente a $53,9 \%$ do efetivo total. Na tabela 2 demonstramos que essa supremacia não reflete diretamente no quadro de docentes permanentes dos Programas de Pós-graduação em Ciências da Religião no Brasil, onde o efetivo feminino corresponde a apenas $21,8 \%$ do total.

$\mathrm{Na}$ tabela 3 verifica-se que o total de autoras que participaram do Compêndio em Ciência da Religião corresponde a 21,2\% do efetivo total de autores.

Dois dados chamam a atenção na tabela 3: 1) a ausência de pesquisadoras na análise epistemológica (metateórica); 2) a ausência de pesquisadoras na análise da aplicabilidade (prática) das Ciências da Religião. Daí se conclui que a participação feminina na composição do Compêndio foi restrita às disciplinas auxiliares: Ciências Sociais, Ciências Psicológicas e Ciências das Linguagens. Frisamos não ser possível afirmar categoricamente que esse "não-lugar de sua palavra" (Èlizabeth LACELLE, 2002, p. 22) atende deliberadamente a princípios patriarcais ou androcêntricos promovidos pelos programas. No entanto, retrata um dado sociocultural presente também nas instituições acadêmicas, ainda que de forma velada ou inconsciente, sob a ação de uma "não-tradição acadêmica" (Èlizabeth LACELLE, 2002, p. 30).

Deve-se considerar que se trata de todas as áreas, e não especificamente das Ciências da Religião. No entanto, não se pode desconsiderar a questão da proporção. 
Tabela 3 - Autores do Compêndio de Ciência da Religião

\begin{tabular}{l|c|c|c}
\hline \multicolumn{1}{c|}{ Compêndio } & Total de Autores & Masculino & Feminino \\
\hline Parte I - Epistemologia & 11 & 11 & 00 \\
\hline $\begin{array}{l}\text { Parte II - Ciências } \\
\text { Sociais }\end{array}$ & 10 & 07 & 03 \\
\hline $\begin{array}{l}\text { Parte III - Ciências } \\
\text { Psicológicas }\end{array}$ & 13 & 08 & 05 \\
\hline $\begin{array}{l}\text { Parte IV - Ciências das } \\
\text { Linguagens }\end{array}$ & 09 & 06 & 03 \\
\hline $\begin{array}{l}\text { Parte V - Ciência da } \\
\text { Religião Aplicada }\end{array}$ & 09 & 09 & 00 \\
\hline Total & $\mathbf{5 2}$ & $\mathbf{4 1}$ & $\mathbf{1 1}$ \\
\hline Proporção & $\mathbf{1 0 0 \%}$ & $\mathbf{7 8 , 8 \%}$ & $\mathbf{2 1 , 2 \%}$ \\
\hline
\end{tabular}

Fonte: dados elaborados pelo autor a partir da análise do Compêndio de Ciência da Religião

\section{CONCLUSÃO}

As análises estatísticas realizadas nesse artigo demonstraram quantitativamente que há uma compartimentação do espaço acadêmico/ profissional reservado às pesquisadoras da religião. Consideramos que esse dado quantitativo não indica, por si só, que há uma intencionalidade nessa compartimentação. As causas dessas disparidades só podem ser determinadas mediante a realização de estudos extensos e específicos, não comportados em um artigo científico. Ao método religiográfico compete o diagnóstico, o estado da arte dos estudos sobre religião. Os diagnósticos levantados carecem de outros olhares e da aplicação de outros métodos de análise.

A despeito da possibilidade de compartimentação da participação das pesquisadoras femininas (não necessariamente feministas), não se pode negar que, além da importância dos aspectos emancipatórios, a contribuição feminina é de vital importância para o estabelecimento de um estatuto epistemológico na consolidação da área no cenário acadêmico/institucional. Nesse sentido, "as teorias feministas têm uma contribuição fundamental para as Ciências da Religião ao incluírem o mundo da vida e da religião das mulheres como fundamentos centrais para a pesquisa" (Ana Ester FREIRE, p. 377, 2015). 


\section{REFERÊNCIAS}

DREHER, Luiz Henrique. Ciência(s) da religião: teoria e pós-graduação no Brasil. In: TEIXEIRA, Faustino (org.). A(s) ciência(s) da religião no Brasil: afirmação de uma área acadêmica. São Paulo: Paulinas, 2008, pp. 151-178.

CAMURÇA, Marcelo. Ciências Sociais e Ciências da Religião: polêmicas e interlocuções. São Paulo: Paulinas, 2008.

CIARALLO, Gilson. Estudos da secularização do Brasil nas ciências sociais: entre a explicação sociológica e a compreensão de individualidades históricas. Universitas

Humanas, Brasília, v. 6, n. 1, jan./jun. 2009, pp. 41-58.

COORDENAÇÃO de Aperfeiçoamento de Pessoal de Nível Superior - CAPES. Mulheres são maioria na pós-graduação brasileira. Disponível em: <https://www.capes.gov.br/36-noticias/8315-mulheres-sao-maioria-na-pos-graduacao-brasileira>. Acesso em 19 nov. 2019. CRESPO, Antônio Arnot. Estatística fácil. São Paulo: Saraiva, 1996.

FERREIRA, Amauri Carlos Ferreira; SENRA, Flávio. As Ciências da Religião no Brasil: contribuições de uma disciplina ao debate sobre o fato religioso. Análise a partir da produção docente dos PPGCRs. Belo Horizonte: Pontifícia Universidade Católica de Minas Gerais, 2013.

FERREIRA, Amauri Carlos; SENRA, Flávio. Tendência Interdisciplinar das Ciências da Religião no Brasil. O debate epistemológico em torno da interdisciplinaridade e o paralelo com a constituição da área no país. Numen, Juiz de Fora, v. 15, n.2, dez. 2012, p. 249269. Disponível em: <http//numen.uff.emnuvens.com.br/numen/article/view/1729/1446>. Acesso em 13 out. 2016.

FREIRE, Ana Ester Pádua. Epistemologia feminista: contribuições para o estudo do fenômeno religioso. Paralellus, Recife, n. 13, jul./dez. 2015, pp. 377-390. Disponível em: < http://www.unicap.br/ojs/index.php/paralellus/article/view/647>. Acesso em 22 mar. 2019. GIL, Antônio Carlos. Métodos e técnicas de pesquisa social. São Paulo: Atlas, 1999. JENSEN, Jeppe Sinding; CRUZ, Eduardo Rodrigues. Epistemologia. Rever, São Paulo, n. 2, jul./dez. 2013, pp. 171-191.

JUNGES, Alexandre Luis Junges, Desacordo racional e controvérsia científica. Scientiæ Zudia, São Paulo, v. 11, n. 3, 2013, pp. 613-635

KUHN, Thomas. The Structure of Scientific Revolutions. Chicago: The University of Chicago Press, 1996.

LACELLE, Èlizabeth J. As Ciências Religiosas Feministas: estado da questão. REVER, n. 1, 2002, pp. 12-55. Disponível em: <www.pucsp.br/rever/rv1_2002/p_lacell.pdf >. Acesso em 18 dez. 2019.

MARQUES, Ângela Cristina Borges; ROCHA, Marcelo. Memórias da fase inicial da Ciência da Religião no Brasil: entrevistas com Edênio Valle, José J. Queiroz e Antônio Gouveia Mendonça. REVER, São Paulo, mar. 2007, pp. 192-214. 
MENDONÇA, Antônio Gouveia. Ciências da religião: de que mesmo estamos falando? Ciências da Religião História e Sociedade, São Paulo, ano 2, n. 2, 2004, pp. 16-34.

MENDONÇA, Antônio de Gouveia. A cientificidade das ciências da religião. In: TEIXEIRA, Faustino (Org.). A(s) ciência(s) da religião no Brasil: afirmação de uma área acadêmica. São Paulo: Paulinas, 2008, pp. 103-151.

PASSOS, João Décio; USARSKI, Frank (Orgs.). Compêndio de Ciência da Religião. São Paulo: Paulus/Paulinas, 2013.

PONDÉ, Luiz Felipe. Em busca de uma cultura epistemológica. In: TEIXEIRA, Faustino (Org.). A(s) Ciência(s) da Religião no Brasil: afirmação de uma área acadêmica. São Paulo: Paulinas, 2008, pp. 11-66.

RAGO, Margareth. Epistemologia feminista, gênero e história. In: PEDRO, Joana; GROSSI, Miriam (Orgs.). Masculino, feminino, plural. Florianópolis: Ed. Mulheres, 1998. Disponível em: <http://projcnpq.mpbnet.com.br/textos/epistemologia_feminista.pdf>. Acesso em: 27 out. 2019.

SAUSSAYE, Pierre Daniel Chantepie, Manual of the science of religion. London: Longmans, Green and Company, 1891.

SENRA, Flávio. Estudos de Ciência(s) da(s) religião(ões) e teologia no Brasil: Situação atual e perspectivas. REVER, São Paulo, v. 15, n. 2, 2015, pp. 196-214. Disponível em: $<$ http//revistas.pucsp.br/index.php/rever/article/view/26196/18859>. Acesso em 12 out. 2016.

SOUZA, Sandra Duarte de. Revista Mandrágora: gênero e religião nos estudos feministas. Estudos Feministas. Florianópolis, n. 12, set./dez., 2004, pp. 122-130 . Disponível em: <http://www.scielo.br/scielo.php?pid=S0104-026X2004000300014\&script=sci_arttext>. Acesso em 17 out. 2019.

USARSKI, Frank. Constituintes da ciência da religião. São Paulo: Paulinas, 2006.

Submetido em: 6-5-2020

Aceito em: 10-9-2020 